\title{
Evaluation of spray drift in potatoes using various spray delivery systems
}

\author{
R.L. Roten ${ }^{1}$, J.C. Ferguson ${ }^{2}$ and A.J. Hewitt ${ }^{1,3}$ \\ ${ }^{1}$ Lincoln Agritech, Engineering Drive, Lincoln 7640, New Zealand \\ ${ }^{2}$ PO Box 84, Lincoln University, New Zealand \\ ${ }^{3}$ The University of Queensland, Gatton QLD 4343, Australia \\ Corresponding author: rory.roten@lincolnagritech.co.nz
}

Spray deposition has previously been studied within a potato canopy. In a follow-up study, spray drift was evaluated using three treatments from the previous research plus two treatments encompassing an additional grower standard and a spray drift standard. Treatments included (1) an air-assisted Gambetti sprayer with full-cone nozzles applying spray at a rate of 400 litres/ha, (2) a rotary atomizer spraying system (Proptec) applying spray at a rate of 200 litres/ha, (3) a drop-leg application spraying above (25\%) and below canopy (75\%) at 260 litres/ha, (4) a conventional hydraulic nozzle spray boom with Guardian AIR ${ }^{\mathrm{TM}}$ Twin nozzles applying 200 litres/ha and (5) a conventional hydraulic nozzle spray boom with standard 11003 nozzles at 300 litres/ha. Data were normalized per nozzle and application rate (200 litres /ha). With the exception of the Gambetti application, results indicated a similar pattern with very low deposition beyond $10 \mathrm{~m}$ downwind. The Gambetti results showed very low deposition near $0 \mathrm{~m}$ and spray cloud reaching $40 \mathrm{~m}$, but it is believed that the turbulent airflow from the Gambetti sprayer adversely affected the deposition samplers through a high level of disturbance, so more data are necessary for further analysis of this effect. 